\title{
Intonation Pattern Analysis of Phonemes in MISING Language
}

\author{
Rizwan Rehman \\ Centre for Computer Studies \\ Dibrugarh University
}

\author{
Gopal Chandra Hazarika \\ Department of Mathematics \\ Dibrugarh University
}

\author{
Devid Kardong \\ Department of Life Sciences \\ Dibrugarh University
}

\begin{abstract}
Intonation is one the basic building blocks of the prosody. The fundamental frequency (F0) represents the intonation acoustically. This is the first study into the analysis of intonation pattern in MISING language. In MISING language it is found that the syllables occur at a regular interval and hence it is syllable timed. Since the syllables are the phonological building blocks of a word they can influence the rhythm of the language and also its pattern of stress apart from other factors. The present study aims at finding the intonation pattern of words in MISING language. Words of the structure VCV, VCVC, VCCV, VCCVC, CVCV, CVCVC, CVCCV and VCCCVC are observed and analyzed both in terms of pitch variations and fundamental frequency (F0) the pitch contour are also analyzed in this paper. The tone pattern are marked with the help of Tone and Break Index model (ToBI)
\end{abstract}

\section{Keywords}

Natural Language Processing, Intonation, Fundamental frequency, Pitch, ToBI, Syllable, MISING

\section{INTRODUCTION}

Intonation refers to the pitch or tune of the utterance [Ladd 1996]. It is one of the major components of the prosody. Intonation as such is not used to distinguish words but it has some major function such as indicating the attitude and emotion of the speaker as well as differentiating factors between a statement and a question [Ladd 2000]. The speaker can convey the meaning of the word by employing pitch in different ways. Pitch can be analyzed using fundamental frequency (F0) of the speaker's vocal cord while speaking a sentence.

There are four classes into which intonation pattern are categorized:
i. Pitch increase over time
ii. Pitch decrease over time
iii. Pitch fall and rise
iv. Pitch rise and fall

In linguistics it is often found that a same set of words can be associated with different tunes which can be done by rising or falling pitch [Liberman and Prince 1977]. While speaking a sentence the intonation which is associated can be heard along with some relatively prominent word or accented words. This phenomenon is found because the pitch accent which is the unit of intonation is synchronized with the vowel of the primary stress syllable of each word that is accented. These intonation patterns are language dependent.

\section{STRUCTURE OF SYLLABLE AND WORD}

Syllables are the phonological building block of the words. Syllables have an impact on the rhythm of the language its prosody and stress pattern. Syllabic nucleus is the main component of the syllable which is occupied by vowel.

In almost all the major language across the globe, vowels form the nucleus. The vowels that precede the nucleus are the ONSET and vowels after the nucleus are called the CODA [Selkirk 1984].

The nucleus of the syllable is sonorant, which makes the vowel sound in the form of monopthong, dipthong and tripthong.

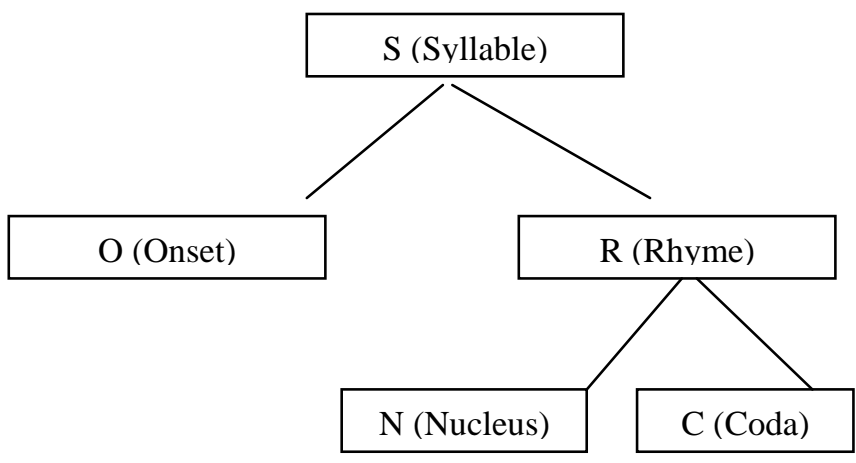

Fig 1: Syllable Structure

Every syllable will consist of nucleus. Many languages in their syllable part have Onset such as CV, CVC. If the coda is absent such as V, CCV then such syllable are open syllable or free syllable while the syllable which have Coda such as VC, CVC are called closed syllable. Open syllable are found in almost all the languages.

\section{MISING LANGUAGE}

Mising language is a subgroup of Tibeto-Burman group of languages and most of the syllables in MISING language are disyllabic in nature. The basic syllabic structure in MISING language is represented as $(\mathrm{C}) \mathrm{V}(\mathrm{C})$ where $\mathrm{V}$ is a vowel and $\mathrm{C}$ is consonant. MISING language is syllable timed or pitched time in nature.

Table 1. Syllabic Structure in MISING Language

\begin{tabular}{|c|c|c|}
\hline STRUCTURE & $\begin{array}{c}\text { WORD } \\
\text { (DISYLLABIC) }\end{array}$ & MEANING \\
\hline V C V & alé & leg \\
\hline V C V C & amír & body \\
\hline V C C V & émpu & large mat \\
\hline
\end{tabular}




\begin{tabular}{|c|c|c|}
\hline V C C V C & argom & rust \\
\hline CV CV & ke:di: & mango \\
\hline CV CVC & sípund & rainwater \\
\hline CVC CV & kampo & white \\
\hline VCC CVC & sormon & crocodile \\
\hline
\end{tabular}

Word stress in MISING language is a weak phenomenon. MISING speech is therefore syllable timed. The prominent fact that makes word stress a weak phenomenon is that for every short vowel in MISING language there is a corresponding long vowel. Other fact being that the short vowels are all equal in terms of prominence and the long vowels are relatively more prominent but may or may not be stressed in the normal speech.

As against the absence of tone there exists multiple pattern of intonation in MISING language. These patterns vary from dialect to dialect. However, the PAGRO and DELU group of MISING community have homogeneity in pattern of intonations.

\section{PITCH CONTOUR}

Speech being a physical phenomenon is a product of sound produced by the vocal chords and filtering which is done by the tongue, lips and teeth. When the sound is produced by the vocal tract the frequency which is produced is called fundamental frequency and its perception is called PITCH frequency generally denoted by F0 (Fundamental Frequency).

Pitch is used in almost many languages in the world to express emotions and other paralingual information.

Pierrehumbert's [Pierrehumbert 1980] argued that intonation could be described in terms of two basic tones which is called $\mathrm{H}$ (high) and $\mathrm{L}$ (low). Pitch accents can be represented as either single or double tone [Pike 1945]. The possible pitch accents are $\mathrm{H}^{*}, \mathrm{~L}^{*}, \mathrm{H}^{*}+\mathrm{L}, \mathrm{H}+\mathrm{L}^{*}, \mathrm{~L}+\mathrm{H}^{*}$. The phrase boundary and boundary tones can be found which are marked with $\%$.

\subsection{Tobi}

Tone and Break Index represent the core prosodic analysis. The break index represents the number that exists between the consecutive words. Prominence is used to indicate the strength of the word, syllable or phrase when used in a sentence. Accent is the intonational phenomenon associated with pitch [Ladd, Mennen and Schepman 2000]. Pitch accented tones are marked using TOBI for every accented syllable. If there is no corresponding pitch accent assignment it would mean that the syllable is not accented [Liberman 1975]. The following four categories of assignment can be done using TOBI model:

i. $\mathrm{H}^{*}$ - Peak Accent (Upper part of speakers pitch range in phrase)

ii. L* - Low Accent (Lowest part of speakers pitch)

iii. $\mathrm{L}^{*}+\mathrm{H}-$ Scooped accent (low tone target which is followed by relatively sharp rise to a peak)

iv. $\mathrm{L}+\mathrm{H}^{*}-$ Rising peak accent (High peak target which is immediately preceded by relatively sharp rise)

\section{EXPERIMENTAL SETUP}

In the present analysis some phonetically balanced phonemes of MISING language were selected with the help of language

experts in the MISING language from the Centre for Language Studies, Dibrugarh University. The objective is to study the intonation pattern. The data set consist of a block of 29 words of MISING language and 14 vowels. A group of 5 male and 5 female native speaker of age between 20 to 45 years has been considered for recording the data. The recording was done using PRAAT software and PHILIPS head mounted microphone in a small room with minimum background noise. The speech signal was then digitized at $22.5 \mathrm{KHz}$. The theoretical model used is TOBI a system developed by Beckham and Pierrehumbart for making high and low tone targets in a word.

Pitch setting for the recording was as follows:

i. For male: floor $-75 \mathrm{~Hz}$ ceiling- $300 \mathrm{~Hz}$

ii. For female: floor- $100 \mathrm{~Hz}$ ceiling- $600 \mathrm{~Hz}$

\subsection{Experimental Results}

Table 2. Tone pattern of MISING words for both male and female utterances

\begin{tabular}{|c|c|c|c|c|}
\hline $\begin{array}{l}\text { Word } \\
\text { Structure }\end{array}$ & Word & $\begin{array}{l}\text { Max } \\
\text { FO(Hz) }\end{array}$ & $\begin{array}{l}\text { Min F0 } \\
(\mathrm{Hz})\end{array}$ & $\begin{array}{l}\text { Tone } \\
\text { Pattern }\end{array}$ \\
\hline \multirow{5}{*}{ V-CV } & Alé & 155.16 & 117.59 & $\begin{array}{c}\mathrm{L} \\
\mathrm{H} \%\end{array}$ \\
\hline & Akí & 161.85 & 108.24 & $\mathrm{~L}$ \\
\hline & & & & $\mathrm{H} \%$ \\
\hline & Anyi & 151.28 & 117.67 & $\begin{array}{c}\mathrm{L} \\
\mathrm{H} \%\end{array}$ \\
\hline & Épo & 149.12 & 119.45 & $\begin{array}{c}\mathrm{L} \\
\mathrm{H} \%\end{array}$ \\
\hline \multirow{4}{*}{ VC-VC } & Okum & 185.19 & 125.49 & $\begin{array}{c}\mathrm{L} \\
\mathrm{H} \%\end{array}$ \\
\hline & Apong & 176.32 & 116.77 & $\begin{array}{c}\mathrm{L} \\
\mathrm{H} \%\end{array}$ \\
\hline & Oyan & 173.61 & 122.46 & $\begin{array}{c}\text { L } \\
\mathrm{H} \%\end{array}$ \\
\hline & Amir & 157.27 & 119.52 & $\begin{array}{c}\mathrm{L} \\
\mathrm{H} \%\end{array}$ \\
\hline \multirow[t]{4}{*}{ VC-CV } & Anné & 183.88 & 128.88 & $\begin{array}{c}\mathrm{L} \\
\mathrm{H} \%\end{array}$ \\
\hline & Agro & 158.72 & 108.39 & $\begin{array}{c}\mathrm{L} \\
\mathrm{H} \%\end{array}$ \\
\hline & Amro & 153.17 & 119.66 & $\begin{array}{c}\mathrm{L} \\
\mathrm{H} \%\end{array}$ \\
\hline & Émpo & 174.01 & 126.48 & $\begin{array}{c}\mathrm{L} \\
\mathrm{H} \%\end{array}$ \\
\hline \multirow[t]{3}{*}{ VC-CVC } & Argom & 171.68 & 120.41 & $\begin{array}{c}\mathrm{L} \\
\mathrm{H} \%\end{array}$ \\
\hline & Éllung & 176.12 & 132.65 & $\begin{array}{c}\mathrm{L} \\
\mathrm{H} \%\end{array}$ \\
\hline & Otsur & 163.33 & 109.18 & L \\
\hline
\end{tabular}




\begin{tabular}{|c|c|c|c|c|}
\hline & & & & $\mathrm{H} \%$ \\
\hline & Ogyum & 176.52 & 123.67 & $\begin{array}{c}\mathrm{L} \\
\mathrm{H} \%\end{array}$ \\
\hline \multirow{4}{*}{ CV-CV } & Péki & 178.95 & 130.67 & $\begin{array}{c}\mathrm{L} \\
\mathrm{H} \%\end{array}$ \\
\hline & Péji & 178.75 & 124.26 & $\begin{array}{c}\mathrm{L} \\
\mathrm{H} \%\end{array}$ \\
\hline & Koné & 167.67 & 129.85 & $\begin{array}{c}\mathrm{L} \\
\mathrm{H} \%\end{array}$ \\
\hline & Bíkí & 174.97 & 116.69 & $\begin{array}{c}\mathrm{L} \\
\mathrm{H} \%\end{array}$ \\
\hline \multirow{3}{*}{ CV-CVC } & Tapad & 159.23 & 125.42 & $\begin{array}{c}\mathrm{L} \\
\mathrm{H} \%\end{array}$ \\
\hline & Siram & 176.83 & 127.11 & $\begin{array}{c}\mathrm{L} \\
\mathrm{H} \%\end{array}$ \\
\hline & Sorog & 160.78 & 123.18 & $\begin{array}{c}\mathrm{L} \\
\mathrm{H} \%\end{array}$ \\
\hline \multirow{3}{*}{ CVC-CV } & Ponta & 175 & 117.88 & $\begin{array}{c}\mathrm{L} \\
\mathrm{H} \%\end{array}$ \\
\hline & Gempa & 174.64 & 116.77 & $\begin{array}{c}\mathrm{L} \\
\mathrm{H} \%\end{array}$ \\
\hline & Kunno & 181.30 & 125.57 & $\begin{array}{c}\mathrm{L} \\
\mathrm{H} \%\end{array}$ \\
\hline \multirow{3}{*}{ CVC-CVC } & Sarkod & 168.37 & 128.22 & $\begin{array}{c}\mathrm{L} \\
\mathrm{H} \%\end{array}$ \\
\hline & Sormon & 181.47 & 126.65 & $\begin{array}{c}\mathrm{L} \\
\mathrm{H} \%\end{array}$ \\
\hline & Dongkal & 129.16 & 93.58 & $\begin{array}{c}\mathrm{L} \\
\mathrm{H} \%\end{array}$ \\
\hline
\end{tabular}
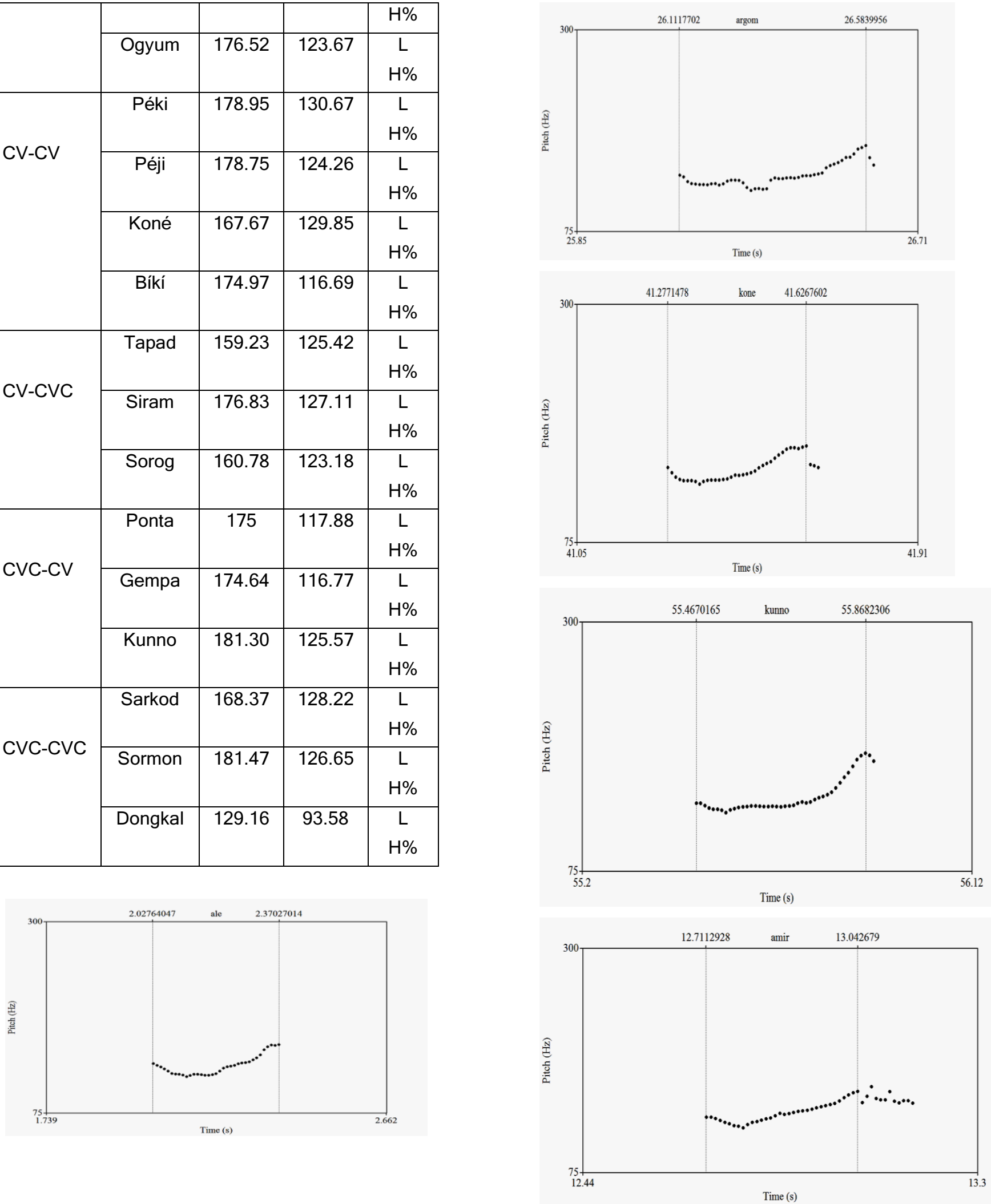

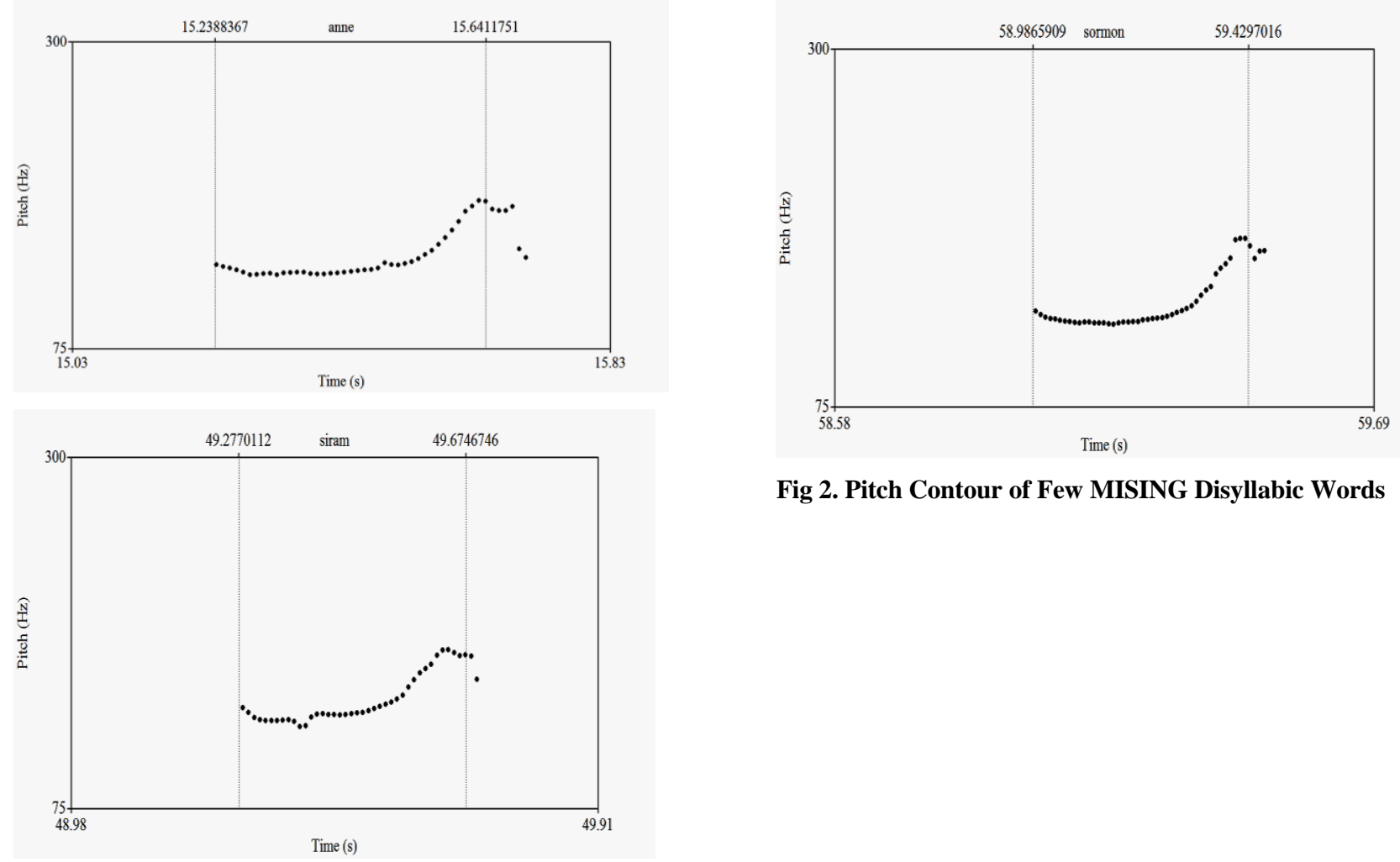

Fig 2. Pitch Contour of Few MISING Disyllabic Words

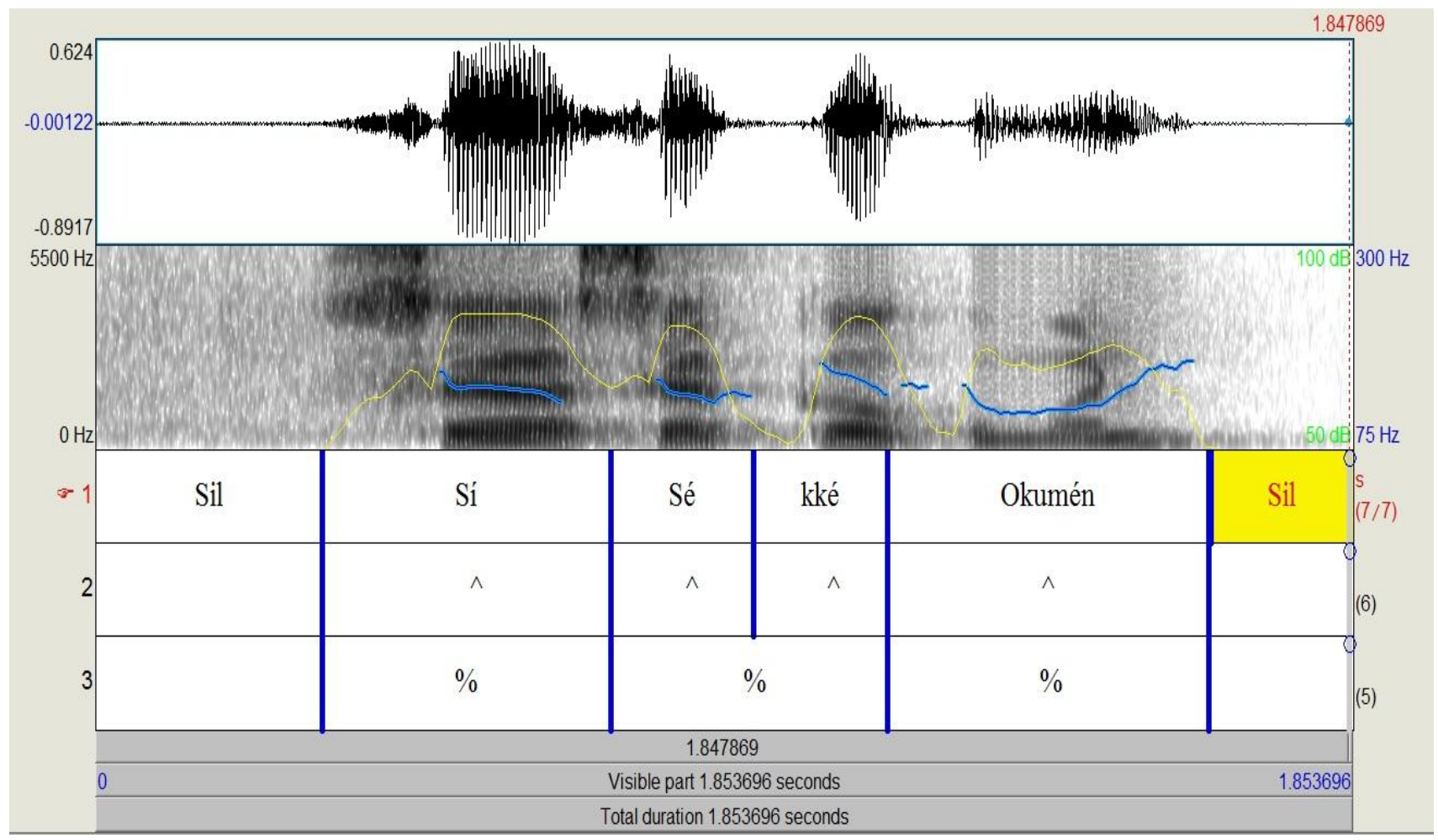




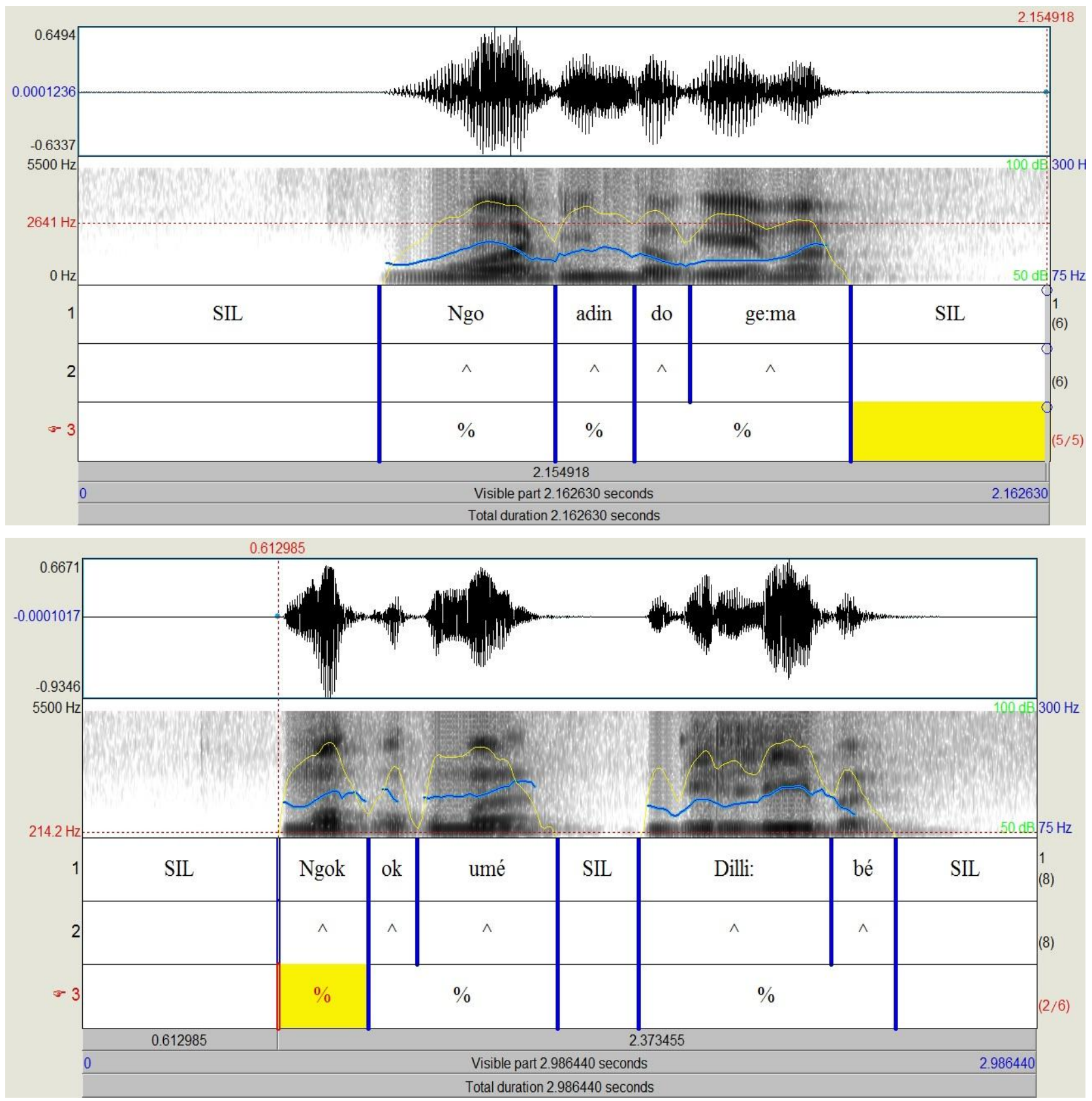

Fig. 3 Example of Intonation Pattern of a Typical MISING Sentence

\section{RESULTS}

1. F0 Contour for vowels in Mising Language shows a rising trend as evident from Fig.2.

2. If the third syllable does not have coda, the stress falls on the first syllable as evident from Fig.2 for words 'argom', 'anne', 'kone', 'siram', 'kumno', 'sormon'.

3. It is found that most of the pitch contour in Fig. 2 starts at a little higher position and then falls and then shows a rising pattern.

4. F0 Contour for vowels in Mising Language shows a rising trend as evident from Fig.2.

5. Fig. 3 shows a typical example of intonation pattern of Mising language. The overall intonation pattern is found to consist of local (minimal) rise and falls of pitch across words or syllable, thus the perception of a sentence is dependent on the pitch pattern of the syllable or word and intonation in general.

\section{CONCLUSION}

On the average the tone pattern shown is LH\%. MISING words do not change their meaning with the change in the pitch of the voice. There are multiple patterns of intonation in the MISING language largely due to the absence of tone. Since the vowe sounds in the syllable are not weakened by the giving stress on adjacent syllable, MISING utterances are therefore syllable timed. The data gathered and the analysis performed in the present study will further help in speech synthesis process.

\section{REFERENCES}

[1] Ladd,D.R., "Intonation Phonology", Cambridge: Cambidge University Press, 1996.

[2] Ladd, D.R., "Declination reset and the hierarchical 
International Journal of Computer Applications (0975 - 8887)

Volume 150-No.5, September 2016

organization of utterances" , Journal of the Acoustical Society of America, 1988.

[3] Liberman, M.Y., and Prince, A. ," On stress and linguistic rhythm”, Linguistic Inquiry 8, 1977.

[4] Selkirk, E.O., "Phonology and Synyax", Cambridge, MA: MIT Press , 1984

[5] Pierrehumbert,J.B., "The phonology and phonetics of English Intonation”, MIT ,1980.
[6] Pike,K.L., "The Intonation of American English", Michigan: University of Michigan(1945)

[7] Ladd,D., Mennen,I. and Schepman, A., "Phonological conditioning of peak alignment in rising pitch accent in Dutch", The journal of Acoustical Society of America,2000 